\title{
Corrigendum: Combinatorial Strategies to Target Molecular and Signaling Pathways to Disarm Cancer Stem Cells
}

\author{
Giuliana Catara, Antonino Colanzi and Daniela Spano* \\ Institute of Biochemistry and Cell Biology, National Research Council, Naples, Italy
}

Keywords: cancer stem cells, cancer, combinatorial strategies, signaling pathways, molecular pathways

\section{A Corrigendum on}

Combinatorial Strategies to Target Molecular and Signaling Pathways to Disarm Cancer Stem Cells

\section{OPEN ACCESS}

Approved by:

Frontiers Editorial Office

Frontiers Media SA, Switzerland

${ }^{*}$ Correspondence:

Daniela Spano

daniela.spano@ibbc.cnr.it

Specialty section:

This article was submitted to Pharmacology of Anti-Cancer Drugs,

a section of the journal

Frontiers in Oncology

Received: 28 July 2021

Accepted: 29 July 2021

Published: 16 August 2021

Citation:

Catara G, Colanzi A and Spano D (2021) Corrigendum: Combinatorial Strategies to Target Molecular and Signaling Pathways to Disarm Cancer Stem Cells.

Front. Oncol. 11:749040. doi: 10.3389/fonc. 2021.749040
By Catara G and Spano D (2021). Front. Oncol. 11:689131. doi: 10.3389/fonc.2021.689131

In the original article, we neglected to include the funder Italian Association for Cancer Research (AIRC, Milan, Italy), IG 2017 id. 20095 to Antonino Colanzi.

\section{ADDITION OF AN AUTHOR}

Antonino Colanzi was not included as an author in the published article. The corrected Author Contributions Statement appears below.

AC discussed and approved the manuscript.

With addition of Dr. Antonino Colanzi to the author list the Acknowledgement will be removed.

The authors apologize for these errors and state that this does not change the scientific conclusions of the article in any way. The original article has been updated.

\footnotetext{
Publisher's Note: All claims expressed in this article are solely those of the authors and do not necessarily represent those of their affiliated organizations, or those of the publisher, the editors and the reviewers. Any product that may be evaluated in this article, or claim that may be made by its manufacturer, is not guaranteed or endorsed by the publisher.

Copyright $\odot 2021$ Catara, Colanzi and Spano. This is an open-access article distributed under the terms of the Creative Commons Attribution License (CC BY). The use, distribution or reproduction in other forums is permitted, provided the original author(s) and the copyright owner(s) are credited and that the original publication in this journal is cited, in accordance with accepted academic practice. No use, distribution or reproduction is permitted which does not comply with these terms.
} 